\title{
S14 物体力相似法による動的連成熱応力問題の解析
}

\author{
Body-Force Analogy for Coupled Dynamic Problems of Thermoelasticity
}

\author{
○正 古川 俊雄（京工繊大）
}

Hans Irschik (Johannes Kepler Univ. Linz)

\begin{abstract}
Toshio FURUKAWA, Kyoto Institute of Technology, Goshokaido-cho, Matsugasaki, Sakyo-ku, Kyoto Hans IRSCHIK, Johannes Kepler University of Linz, Altenbergerstrasse 69, Linz, Austria

The classical body-force analogy for static or quasi-static problems of thermoelasticity is extended towards coupled dynamic problems of thermoelasticity. We consider two dynamic problems, namely a thermal problem without body forces, but with a given distribution of transient sources of heat, and a force problem without sources of heat, but with body forces. Both problems are treated within the context of the coupled dynamic thermoelasticity. We show that, given suitable boundary and initial conditions, a distribution of body forces can be constructed, such that the dynamic displacements or transient temperature in both problems become equal.
\end{abstract}

Key Words: Elasticity, Coupled Dynamic Thermoelasticity, Body Force Analogy, Displacement Compensation

\section{1. 緒言}

静的熱弾性理論において, 古典的な Duhamel の物体力 相似法は次のようになる．与えられた温度の作用下で等方 熱弹性体の静的変形を考えたとき，与えられた温度による 熱変位は，適当な仮想物体力と表面力による等温変位に等 しく，等温応力に仮想圧力を加えることによって熱応力が 求められることを示している(1). 本論文はこの静的物体力 相似法を動的連成熱弾性問題へ拡張することを目的として, 二つの初期値一境界值問題, 寸なわち害際の問題と補助の 問題，を取り扱い，これらの問題における変位がお互いに 打ち消しあう，一般化された形状制御定式化を示す。この 一般化された物体力相似法では，静的物体力相似法は特別 な場合となる。

なお，Irschik ら(2),(3)はこの方法を種々の動的熱弾性問題 に拡張している. 次に我々は温度場とひずみ場の連成を考 慮した動的連成熱応力問題に拡張できることを一次元問題 で示している(4).

\section{2. 基礎方程式}

二つの場を考える.ここでこれらの場における境界条件 と初期条件は等しいと仮定し，これらの場における变位べ

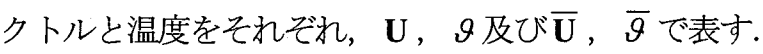

最初の場（直接対象とする場）における基礎方程式は以 下で示される.

運動方程式:

$$
\operatorname{div} \mathbf{S}=\rho \ddot{\mathbf{U}}
$$

応力ーひずみ一温度関係式：

$$
\mathbf{S}=2 \mu \mathbf{E}+\lambda(\operatorname{tr} \mathbf{E}) \mathbf{1}-(3 \lambda+2 \mu) \alpha \vartheta \mathbf{1}
$$

ひずみ一変位関係式：

$$
\begin{gathered}
\mathbf{E}=\frac{1}{2}\left(\nabla \mathbf{U}+\nabla \mathbf{U}^{T}\right) \\
\text { エネルギー方程式 : } \\
-\operatorname{div} \mathbf{q}+r=c_{E} \rho \dot{\vartheta}+(3 \lambda+2 \mu) \alpha \theta_{0} \operatorname{tr} \dot{\mathbf{E}}
\end{gathered}
$$

熱方程式:

$$
\mathbf{q}=-k \nabla \vartheta
$$

第二の場（仮想している場）における基礎方程式は以下 で示される.

運動方程式：

$$
\operatorname{div} \overline{\mathbf{S}}+\overline{\mathbf{b}}=\rho \ddot{\overline{\mathbf{U}}}
$$

応力ーひずみー温度関係式 :

$$
\overline{\mathbf{S}}=2 \mu \overline{\mathbf{E}}+\lambda(\operatorname{tr} \overline{\mathbf{E}}) \mathbf{1}-(3 \lambda+2 \mu) \alpha \bar{\vartheta} \mathbf{1}
$$

ひずみー変位関係式：

$$
\overline{\mathbf{E}}=\frac{1}{2}\left(\nabla \overline{\mathbf{U}}+\nabla \overline{\mathbf{U}}^{T}\right)
$$

エネルギー方程式：

$$
-\operatorname{div} \overline{\mathbf{q}}=c_{E} \rho \dot{\bar{\vartheta}}+(3 \lambda+2 \mu) \alpha \theta_{0} \operatorname{tr} \dot{\overline{\mathbf{E}}}
$$

熱方程式：

$$
\overline{\mathbf{q}}=-k \nabla \bar{\vartheta}
$$

ここで, $\mathbf{S}, \overline{\mathbf{S}}$ は応力テンソル $, \mathbf{E}, \overline{\mathbf{E}}$ はひずみテンソル を表す. $\rho$ 滵度, $\lambda, \mu$ はラーメの定数, $c_{E}$ は定積比 熱 $\alpha$ は線膨張係数， $k$ は熱伝導率であり，これらの定数に は温度依存性がないものとする， $\theta_{0}$ は無応力状態における 絶対温度を表す， $r$ は熱源であり，この場においては既知 とする。 நは物体力ベクトルである。 また，コンマはそれ に続く変数による微分を表し，上付きドットは時間微分を 表す.

式(4), (9)の右辺第 2 項が温度場とひずみ場を関係づける 連成項である.

なお，数学演算の正当性を保つため，式(1)～(5)，式(6) 〜(10)で導入された場は十分なめらかであるとする.

最初の場において，式(3)，(5)を式(4)に代入することによ り次式が得られる.

$$
k \nabla^{2} \vartheta=c_{E} \rho \dot{\vartheta}+(3 \lambda+2 \mu) \alpha \theta_{0} \dot{e}-r
$$


ただし，eは体積ひずみである.

式(2)，(3)を式(1)に代入すると

$$
\mu \nabla^{2} \mathbf{U}+(\lambda+\mu) \nabla e-(3 \lambda+2 \mu) \alpha \nabla \vartheta=\rho \ddot{\mathbf{U}}
$$

同様な手順により，第二の場に対して

$$
k \nabla^{2} \bar{\vartheta}=c_{E} \rho \dot{\bar{\vartheta}}+(3 \lambda+2 \mu) \alpha \theta_{0} \dot{\bar{e}}
$$

$$
\mu \nabla^{2} \overline{\mathbf{U}}+(\lambda+\mu) \nabla \bar{e}-(3 \lambda+2 \mu) \alpha \nabla \bar{\vartheta}+\overline{\mathbf{b}}=\rho \ddot{\overline{\mathbf{U}}}
$$

となる. これ以降, 式(11), (12)に従う問題は熱の問題と表 し，式(13)，(14)に従う問題は力の問題と表すことにする. さて, 次のような新しい記号を導入する.

$$
\mathbf{U}^{*}=\mathbf{U}-\overline{\mathbf{U}}, \quad \Theta^{*}=\vartheta-\bar{\vartheta}
$$

式(12)，(14) と式(11)，(13)から次式が得られる.

$$
\begin{aligned}
& \mu \nabla^{2} \mathbf{U}^{*}+(\lambda+\mu) \nabla e^{*}-(3 \lambda+2 \mu) \alpha \nabla \Theta^{*}-\overline{\mathbf{b}}=\rho \ddot{\mathbf{U}}^{*} \\
& k \nabla^{2} \Theta^{*}=c_{E} \rho \dot{\Theta}^{*}+(3 \lambda+2 \mu) \alpha \theta_{0} \dot{e}^{*}-r
\end{aligned}
$$

古典的な物体力相似法を動的連成熱弾性問題に拡張する ことを考え， $\mathbf{U}^{*}=\mathbf{0}$ という条件を求めることにする. なお, 同様な考え方で $\Theta^{*}=0$ という条件を求めることもできる.

式(11)において熱源は既知であるので，熱の問題と力の 問題における变位が等しくなるような物体力 $\overline{\mathbf{b}}$ を求めるこ とにする.

\section{3. 新しい物体力相似法}

前節で述べた物体力相似法に対する解を求める第一段階 は次のようにする.

$$
\overline{\mathbf{b}}=-(3 \lambda+2 \mu) \alpha \nabla \Theta^{*}
$$

と仮定すると式(16)は

$$
\mu \nabla^{2} \mathbf{U}^{*}+(\lambda+\mu) \nabla e^{*}=\rho \ddot{\mathbf{U}}^{*}
$$

となる. 仮定により得られる同次境界条件と同次初期条件 を用いると， $\mathbf{U}^{*}=\mathbf{0}$ が解となる，これは

$$
\mathbf{U}=\overline{\mathbf{U}}
$$

であり，適切な大きさの物体力を利用することにより変位 制御が可能であることを意味している.

しかしながら，式(18)のままでは物体力 $\overline{\mathbf{b}}$ は求められな いので，次に物体力 $\mathbf{b}$ を特定することにする.

式(18)に div を作用させると

$$
\nabla^{2} \Theta^{*}=-\frac{1}{(3 \lambda+2 \mu) \alpha} \operatorname{div} \overline{\mathbf{b}}
$$

上式を用いると式(17)は次のようになる.

$$
-\frac{k}{(3 \lambda+2 \mu) \alpha} \operatorname{div} \overline{\mathbf{b}}=c_{E} \rho \dot{\Theta}^{*}+(3 \lambda+2 \mu) \alpha \theta_{0} \dot{e}^{*}-r
$$

さらに

$$
\begin{aligned}
-\frac{k}{(3 \lambda+2 \mu) \alpha} \nabla^{2} \overline{\mathbf{b}} & =-\frac{c_{E} \rho}{(3 \lambda+2 \mu) \alpha} \dot{\overline{\mathbf{b}}} \\
& +(3 \lambda+2 \mu) \alpha \theta_{0} \nabla \dot{e}^{*}-\nabla r
\end{aligned}
$$

が得られる。

したがって, $\mathbf{U}^{*}=\mathbf{0}$ と仮定すると次のような物体力 $\overline{\mathbf{b}}$ に 関する微分方程式を得ることができる.

$$
\nabla^{2} \overline{\mathbf{b}}-\frac{c_{E} \rho}{k} \dot{\mathbf{b}}=\frac{(3 \lambda+2 \mu) \alpha}{k} \nabla r
$$

言い換えると， $\mathbf{U}^{*}=\mathbf{0}$ が式(17)の解であることが保証でき ると,式(24)は熱源 $r$ による熱の問題と等しくなるような物 体力堛計算するのに用いることができる.

力学的境界条件と熱的境界条件および初期条件として次 の場合を考える.

$$
\begin{aligned}
& \text { b.c. } \mathbf{U}^{*}=\mathbf{0}, \nabla \Theta^{*}=0 \\
& \text { i.c. } \mathbf{U}^{*}=\mathbf{0}, \dot{\mathbf{U}}^{*}=\mathbf{0}, \Theta^{*}=0
\end{aligned}
$$

\section{4. 解 析 例}

領域が， $0 \leq X \leq L$ である一次元物体を考える．この とき， $\bar{b}$ に対する境界条件と初期条件は

$$
\text { b.c. } \bar{b}=0 \quad \text { i.c. } \bar{b}=0
$$

となる，例として次の場合を考える.

$$
r=r_{0} \cos \frac{\pi X}{L} \exp (-a t)
$$

ここで， $r_{0}$ と $a$ は任意の正の定数である.

境界条件を満足するように, 物体力を次式で表す。

$$
\bar{b}=\bar{b}_{0} \sin \frac{\pi X}{L} \exp (-a t)
$$

式(27)，(28)を式(24)に代入すると次式が得られる.

$$
\bar{b}=\frac{\frac{\pi}{L} \frac{(3 \lambda+2 \mu) \alpha}{k}}{\left(\frac{\pi}{L}\right)^{2}-\frac{c_{E} \rho}{k} a} r_{0} \sin \frac{\pi X}{L} \exp (-a t)
$$

式(27)，(29)を式(16)，(17)に代入し， $U^{*}$ と $\Theta^{*}$ に関 する連立方程式を解くと

$$
\begin{aligned}
& U^{*}=0 \\
& \Theta^{*}=\frac{1}{\left(\frac{\pi}{L}\right)^{2}-\frac{c_{E} \rho}{k} a} \frac{r_{0}}{k} \cos \frac{\pi X}{L} \exp (-a t)
\end{aligned}
$$

これより期待された式を導くことができた.

\section{5. 結 言}

動的連成熱応力問題に対して物体力相似法を適用し た．物体力または熱源のない二つの場を考え，それぞ れ，熱の問題と力の問題と名づけ，熱の問題における 変位と等しくなるように, 力の問題における物体力を 求めることができることを示した。この方法は温度を 等しくする場合にも用いることができる.

\section{文 献}

（1）例えば, Noda, N., Hetnarski, R. B., and Tanigawa, Y., Thermal Stresses, Lastran (2000), New York.

(2) Irschik, H. and Pichler, U., Dynamic Shape Control of Solids and Structures by Thermal Expansion Strains, J. Thermal Stresses, 24 (2001), 565-578.

(3) Irschik, H. and Pichler, U., An Extension of Neumann's Method for Shape Control of Force-induced Elastic Vibrations by Eigenstrains, Int. J. Solids Struct., 41 (2004), 871-884.

(4) Furukawa, T. and Irschik, H., Body Force Analogy for One-Dimensional Coupled Dynamic Problems of Thermoelasticity, J. Thermal Stresses, 28 (2005), 455-464. 